\title{
Comparison of methods for quantitating bronchial morphology
}

\author{
CARLOS W. M. BEDROSSIAN,A. E. A N DER O N, JR. ${ }^{1}$ \\ and ALVAN G. FORAKER
}

Research Laboratory, Baptist Memorial Hospital, 800 Prudential Drive, Jacksonville, Florida 32207

To determine the relative accuracy and efficiency of certain methods currently being used to assess bronchial architecture, results obtained with the respective techniques were compared with 'true' values derived from planimetry on the bronchi of 30 subjects. Excellent comparative figures were obtained for each bronchial constituent measured (gland, cartilage, and bronchial wall areas) with the point count method and weighing paper cut-outs. The latter seemed to be the most economical from the standpoint of time saving. Results of Reid indices, acinar counts. and determinations of percentage mucous acini (applicable only to glandular structures) correlated poorly with planimetry.

In the interest of furthering knowledge of bronchial morphology, there is a need for efficient, valid methods of quantitating bronchial architecture. Volumetric measurements would be ideal but are not presently feasible. The Reid index has received widespread attention as a yardstick of one type of bronchial alteration, i.e., bronchial mucous gland hypertrophy (Reid, 1960). This is essentially a one-dimensional approach, relating the thickness of the bronchial gland layer inside the bronchial cartilage to bronchial wall thickness between the epithelium and cartilage in the form of a ratio. Gland acinar counts per microscopic field (Reid, 1960) and the ratio of mucous to serous gland acini (Glynn and Michaels, 1960) have also been suggested as indices of bronchial glandular hypertrophy. The point count technique (Dunnill, Massarella, and Anderson, 1969 ; Macleod and Heard, 1969; Hale, Olsen, and Mickey, 1968) and weighing of paper cut-outs of drawings (Restrepo and Heard, 1963a, 1963b, 1964), both reflecting two-dimensional attempts at greater precision, have been applied to glandular and other bronchial constituents. Despite extensive use of the separate techniques, we know of no systematic analysis of their relative accuracies with respect to bronchial morphology.

Planimetry has been used to study the pulmonary parenchyma and small air passages, and is equally applicable to an assessment of bronchial morphology (Anderson and Foraker, 1962).

${ }^{1}$ Requests for reprints to Dr. Anderson
It is nearly ideal from a precision standpoint (Keuffel \& Esser Company, 1963). It has the dis- o advantages, however, of being tedious and time $\frac{\circ}{\Phi}$ consuming. An alternative procedure, approaching $\stackrel{2}{\Rightarrow}$ planimetry in accuracy but entailing a smaller $\overrightarrow{0}$ quantum of effort, would be desirable. In an endeavour to validate such an alternative? approach, the aforementioned methods, which have been used already to evaluate bronchial morphology, were compared with planimetry in the present analysis.

\section{MATERIAL AND METHODS}

Haematoxylin and eosin stained sections of longitudinal tissue strips from three bronchial levelso (trachea, mainstem, and lobar bronchi) were taken from 30 normal and emphysematous male subjectso of various ages (these will be the subjects of a subsequent report on bronchial alterations in emphysema $N$ and senescence). For technical reasons there were sometimes less than three bronchial samples per case. 은 so that in the final analysis there was a total of $77 \mathrm{\omega}$ bronchial samples for the 30 subjects. Sketches of projected images (magnification $\times 50$ ) on calibrated paper (Keuffel \& Esser Company, $10 \times 10$ to the centimetre) were made from the portion of each bronchialos strip of which the bronchial cartilage was best preserved. Sketches included cartilages, bronchial glands (inside, between, and external to cartilage), artefacts. $\overrightarrow{\mathbb{D}}$ and the boundaries of entire bronchial walls falling $\stackrel{\oplus}{\odot}$ within the field of projection.

'True' areas of bronchial glands and other sketchedo structures were determined planimetrically (mean of three determinations per structure). Areas of the re-O 
spective structures were then obtained with the point count method (mean of three counts). Point counts were made both from sketches and from images projected on a point count grid (points arranged at the angles of centimetres squared).

Reid indices were computed from measurements taken off sketches (mean of three sets of measurements for each bronchial sample taken near the centre and extremities of the concerned cartilage). Gland acinar counts per unit of area and percentage mucous acini were made from $35 \mathrm{~mm}$ colour transparencies of periodic acid-Schiff stained sections $(\times 100)$ (three photographs per bronchial sample were taken in the vicinities already assessed with Reid indices).

Following completion of measurements and indices, individual constituents of bronchial walls were carefully cut out with scissors and weighed with an electrical analytical balance.

The time for making various determinations was carefully recorded in an unselected sample of six cases. Finally, means and correlation indices of the alternative techniques with planimetry were calculated.

\section{RESULTS}

Correlation coefficients between individual methods and planimetry for separate bronchial components of the 30 subjects are shown in Table I. Mean values are given in Tables II to IV. The mean times required for performing all measurements on a single bronchial sample in six of the subjects are shown in Table $\mathrm{V}$.

\section{T A B L E I}

CORRELATION COEFFICIENTS BETWEEN PLANIMETRY AND OTHER QUANTITATIVE PROCEDURES WITH RESPECT
TO BRONCHIAL ARCHITECTURE

\begin{tabular}{|c|c|c|c|}
\hline Procedure & Gland & Cartilage & Bronchial wall \\
\hline $\begin{array}{l}\text { Point count (from } \\
\text { projected image) }\end{array}$ & 0.97 & 0.99 & 0.98 \\
\hline $\begin{array}{l}\text { Point count (from } \\
\text { drawing) } \\
\text { Paper cut-out weighing }\end{array}$ & $\begin{array}{l}0.99 \\
0.99\end{array}$ & $\begin{array}{l}1 \cdot 0 \\
1 \cdot 0\end{array}$ & $\begin{array}{l}0.99 \\
0.99\end{array}$ \\
\hline Acinar counts $\quad$.. & $0 \cdot 24$ & & \\
\hline $\begin{array}{l}\text { Reid index } \ldots \\
\text { Percentage mucous }\end{array}$ & $0 \cdot 34$ & & \\
\hline acini $\quad \ldots \quad \ldots$ & $0 \cdot 12$ & & \\
\hline
\end{tabular}

T A B L E I I

MEAN VALUES ${ }^{1}$ FOR BRONCHIAL GLANDS BY DIFFERENT PROCEDURES

\begin{tabular}{|c|c|c|c|}
\hline Procedure & $\begin{array}{l}\text { Mean } \\
\left(\mathrm{mm}^{2}\right)\end{array}$ & $\begin{array}{c}\text { Standard } \\
\text { Error }\end{array}$ & Range \\
\hline 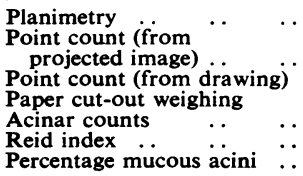 & $\begin{array}{c}1 \cdot 4 \\
1.6 \\
1.4 \\
1 \cdot 5 \\
14 \cdot 8 * \\
0 \cdot 41 \\
76\end{array}$ & $\begin{array}{l} \pm 0.09 \\
\pm 0 \cdot 11 \\
\pm 0.10 \\
\pm 0 \cdot 10 \\
\pm 0.44 \\
\pm 0.013 \\
\pm 2\end{array}$ & $\begin{array}{l}0.04-3.96 \\
0 \cdot 12-5.00 \\
0.04-4 \cdot 08 \\
0.08-4.36 \\
9-26 \\
0.21-0.78 \\
20-100\end{array}$ \\
\hline
\end{tabular}

1 Of 77 bronchial samples (for 30 cases)

* $35 \mathrm{~mm}$ transparency, magnification $\times 100$
T A B L E I I I

MEAN VALUES ${ }^{1}$ FOR CARTILAGE BY DIFFERENT PROCEDURES

\begin{tabular}{|c|c|c|c|}
\hline Procedure & $\underset{\left(\mathrm{mm}^{2}\right)}{\text { Mean }}$ & $\underset{\text { Error }}{\text { Standard }}$ & Range \\
\hline $\begin{array}{l}\text { Planimetry . } \\
\text { Point count (from projected } \\
\text { image) C. } \\
\text { Point count (from drawing) } \\
\text { Paper cut-out weighing }\end{array}$ & $\begin{array}{l}5 \cdot 4 \\
5 \cdot 5 \\
5 \cdot 4 \\
5 \cdot 5\end{array}$ & $\begin{array}{l} \pm 0.29 \\
\pm 0.29 \\
\pm 0.29 \\
\pm 0.29\end{array}$ & $\begin{array}{l}0 \cdot 7-12 \cdot 7 \\
0 \cdot 6-12 \cdot 2 \\
0 \cdot 9-12 \cdot 7 \\
0 \cdot 8-12 \cdot 4\end{array}$ \\
\hline
\end{tabular}

${ }^{1}$ Of 77 bronchial samples (for 30 cases)

\section{T A B L E I V}

MEAN VALUES ${ }^{1}$ FOR BRONCHIAL WALL BY DIFFERENT PROCEDURES

\begin{tabular}{|c|c|c|c|}
\hline Procedure & $\underset{\left(\mathrm{mm}^{2}\right)}{\text { Mean }}$ & Standard & Range \\
\hline $\begin{array}{l}\text { Planimetry . } \\
\text { Point count (from projected } \\
\text { image) } 0 \\
\text { Point count (from drawing) } \\
\text { Paper cut-out weighing } \quad .\end{array}$ & $\begin{array}{l}13 \cdot 8 \\
13 \cdot 9 \\
13 \cdot 7 \\
13 \cdot 8\end{array}$ & $\begin{array}{l} \pm 0.27 \\
\pm 0.26 \\
\pm 0.28 \\
\pm 0.28\end{array}$ & $\begin{array}{l}7 \cdot 4-19 \cdot 6 \\
7 \cdot 6-19 \cdot 6 \\
7 \cdot 6-19 \cdot 6 \\
7 \cdot 6-20 \cdot 0\end{array}$ \\
\hline
\end{tabular}

${ }^{1}$ Of 77 bronchial samples (for 30 cases)

\section{T A B L E V}

MEAN TIME FOR ALL MEASUREMENTS WITH SEPARATE PROCEDURES IN UNSELECTED SAMPLE OF SIX BRONCHI

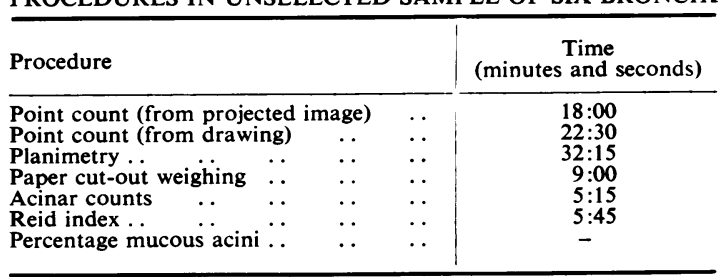

Excellent comparative results were obtained from each bronchial constituent measured with the point count method (whether made from a drawing or from the image projected on a grid) and weighing cut-outs of drawings. Compared with planimetry, there was also a substantial saving in time with the point count method and a considerable saving in time when paper cut-outs were weighed.

Reid indices, acinar counts, and determinations of percentage mucous acini were applicable only to glandular structures. While the time necessary to perform these individual manoeuvres was quite short, results correlated poorly with planimetry. Some sources of potential error with the Reid index and acinar counts are demonstrated in Figures 1 and 2.

\section{DISCUSSION}

Our results seem to indicate that the point count method and weighing of paper cut-outs of 


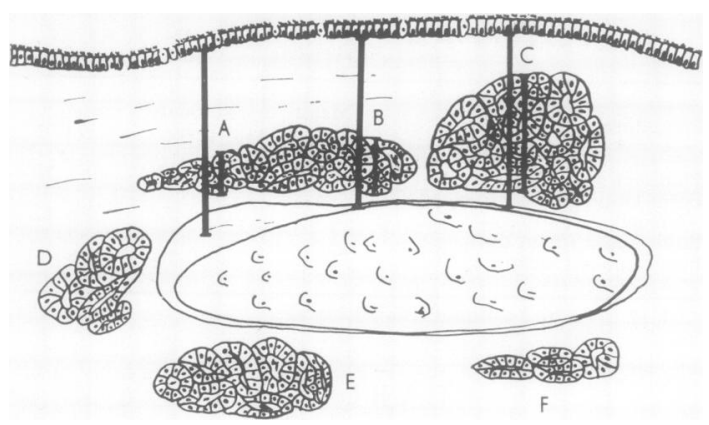

FIG. 1. Some sources of potential errors with the Reid index: All of the following conditions may prevail in a given case. If gland/wall ratio is calculated at $A$, the Reid index obtained is 0.23 but the split between perichondrium and cartilage makes it difficult to define the exact point for the measurement. At $B$, a normal value of 0.36 is obtained, and at $C$, a value of 0.66 . The latter is consistent with bronchitis. Occasionally, glandular nests are present only between and external to cartilage (positions $D, E$, and $F$ ) and not subject to measurement with the Reid index.
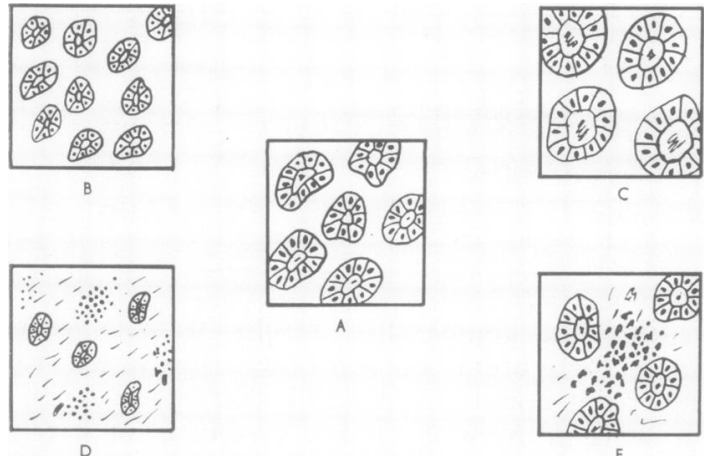

FIG. 2. Some sources of potential errors with acinar counts: There are 6 acini per field in the hypothetical normal sample $(A)$. Nine small acini might occur in a comparable area with atrophy $(B)$, and 4 large with hypertrophy $(C)$. However, in chronic inflammation $(D)$, 4 small acini could occur, separated from each other by fibrosis and round cell infiltration. In acute inflammation $(E)$, a similar situation could prevail, with 4 normal sized acini spread apart by oedema and leukocytic infiltration. These are respective examples of atrophy and normal acini which could be mistaken for gland hypertrophy by the acinar counts.

separate bronchial components are for practical purposes as accurate as planimetry. Moreover, they require less skill and offer a significant saving in time. If the point count method is used, counts made with care from an image projected on a grid seem nearly as good as those made from $a \stackrel{\overline{\bar{c}}}{+}$ drawing of the projected image. Individual ex-? periences and talents will probably influence any $\frac{\bar{\sigma}}{\bar{s}}$ choice in the matter, although weighing cut-outs affords the greatest economy of all in time. It $\propto$ should be emphasized that none of the procedureses is any more accurate than the care taken to per- $\overrightarrow{0}$ form them.

On the basis of our findings, use of the Reid $\vec{\omega}$ index, bronchial glandular acinar counts, and $F$ determination of percentage mucous acini cannot be recommended as indicators of bronchialo mucous gland hypertrophy with any degree of ${ }_{+}^{+}$ precision. While these approaches may have $\vec{\circ}$ value in uncovering gross trends, an experienced? visual impression is probably just as good most ${ }^{\circ}$ of the time.

This work was accomplished with the assistance of $\vec{\varphi}$ grant No. HE-04088 from the National Heart and Lung Institute and grants from the Northeast Florida. Heart Association, Florida Tuberculosis and Respiratory Disease Association, and the Jacksonville Hospitals Educational Program.

\section{REFERENCES}

Anderson, A. E. Jr., and Foraker, A. G. (1962). Relative dimensions of bronchioles and parenchymal spaces in lungs from normal subjects and emphysematous patients. Amer. J. Med., 32, 218.

Dunnill, M. S., Massarella, G. R., and Anderson, J. A. (1969). A comparison of the quantitative anatomy of $x$ the bronchi in normal subjects, in status asthmaticus, $\frac{\sigma}{3}$ in chronic bronchitis, and in emphysema. Thorax, $24, \underline{-}$ 176.

Glynn, A. A., and Michaels, L. (1960). Bronchial biopsy in chronic bronchitis and asthma. Thorax, 15, 142.

Hale, F. C., Olsen, C. R., and Mickey, M. Ray Jr. (1968). The measurement of bronchial wall components. Amer. 음 Rev. resp. Dis., 98, 978.

Keuffel \& Esser Company (1963). Instruction Manual. $\mathrm{N}$ Compensating Polar Planimeters.

Macleod, L. J., and Heard, B. E. (1969). Area of muscle in tracheal sections in chronic bronchitis, measured by $\omega$ point-counting. J. Path., 97, 157.

Reid, L. (1960). Measurement of the bronchial mucous 0 gland layer: a diagnostic yardstick in chronic bronchitis. $\frac{\mathscr{D}}{\mathscr{C}}$ Thorax, 15, 132.

Restrepo, G., and Heard, B. E. (1963a). The size of the bronchial glands in chronic bronchitis. J. Path. Bact., $\bar{O}$ $85,305$.

(1963b). Mucous gland enlargement in chronic $\frac{\curvearrowright}{\mathbb{D}}$ bronchitis: extent of enlargement in the tracheo- $Q$ bronchial tree. Thorax, 18, 334.

- (1964). Air trapping in chronic bronchitis and emphysema. Amer. Rev. resp. Dis., 90, 395. 